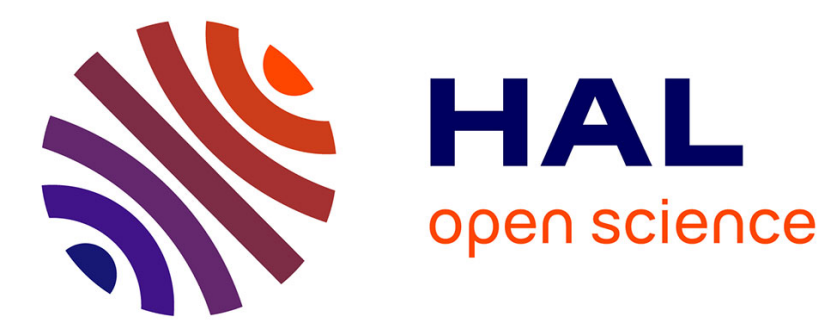

\title{
Representing Children Living with Visual Impairments in the Design Process: A case Study with Personae
}

\author{
Emeline Brulé, Christophe Jouffrais
}

\section{To cite this version:}

Emeline Brulé, Christophe Jouffrais. Representing Children Living with Visual Impairments in the Design Process: A case Study with Personae. CWUAAT 2016, Mar 2016, Cambridge, United Kingdom. pp.23-32, 10.1007/978-3-319-29498-8_3 . hal-01246063v2

\section{HAL Id: hal-01246063 \\ https://hal.science/hal-01246063v2}

Submitted on 1 Feb 2018

HAL is a multi-disciplinary open access archive for the deposit and dissemination of scientific research documents, whether they are published or not. The documents may come from teaching and research institutions in France or abroad, or from public or private research centers.
L'archive ouverte pluridisciplinaire HAL, est destinée au dépôt et à la diffusion de documents scientifiques de niveau recherche, publiés ou non, émanant des établissements d'enseignement et de recherche français ou étrangers, des laboratoires publics ou privés.

\section{(1)(1) $\$(0)$}

Distributed under a Creative Commons Attribution - NonCommercial - ShareAlikel 4.0 


\title{
Representing Children Living with Visual Impairments in the Design Process: A Case Study with Personae
}

\author{
E. Brule, C. Jouffrais
}

\begin{abstract}
Assistive technologies (ATs) must improve activities but also the participation of impaired users. Thus when designing ATs one should consider the diversity of users and disabilities but also the educational and societal contexts, as well as their subjectivities (i.e. personal experience of disability, own motivations, etc.). Co-design is a method that encompasses all those aspects, but it is not easy to achieve with impaired users, especially when they are children. In the context of a research project on interactive maps for visually impaired people, we first conducted a field study to better describe potential users (visually impaired people, but also parents, teachers, therapists, etc.) and their needs. Building upon this fieldstudy, we developed a set of design cards representing users but also needs, places, goals, etc. We then designed a workshop aiming to improve researchers' empathy and knowledge about users in ideation step of the design process. We report on how these methods facilitated the creation of inventive scenarios, interactions and prototypes, but also how they helped researchers to reflect on their own design and research practices.
\end{abstract}

\section{Introduction}

It is estimated that 19 million children live with visual impairment worldwide (WHO 2014). Ensuring their inclusion in society is critical to guarantee equal rights, and because it allows for greater independence. In particular, early inclusion in traditional school has a positive impact on the abilities children develop (McGaha and Farra 2001, Holt et al. 2014). ATs have a role to play, as they can be highly empowering (Hurst and Tobias 2011) and reduce activity limitations. However, previous studies (Phillips and Zhao 1993, Polgar 2010, Kinoe and Noguchi 2014) show a high abandon rate of such devices, underlining the fact that they do not meet needs (usability, reliability, costs, etc.). This may relate to the fact that users are not sufficiently included in the design process (Phillips and Zhao

E. Brule, CNRS \& University Paris Saclay, Telecom ParisTech, Paris, FR. emeline.brule@telecom-paristech.fr

C. Jouffrais, CNRS \& University of Toulouse, IRIT, Toulouse, FR.

Christophe.Jouffrais@,irit.fr 
1993). Moreover, the way children experience their own disability is rarely investigated (Connors and Stalker 2006). There is thus a need to further study how ATs impact the various aspects of disabled children's experiences. Numerous works have shown that having empathy for users is one approach to doing so (Wright and McCarthy 2011).

In the context of designing a collaborative interactive map for visually impaired users, we aimed at encouraging the HCI researchers of our team to better take into account users' context. The activities we proposed aimed at raising their empathy through storytelling and role playing.

In the current paper, we first describe a preliminary field-study aiming at better understanding the educational context and the experiences of visually impaired children. We then present various techniques that we used during a workshop with HCI researchers in order to improve knowledge of users' subjectivities, and to stimulate the production of speculative usage scenarios. Both were conducted as a first step of a longitudinal research project with visually impaired users and caretakers. Although the current work was specific to our context, we aim at providing insights on how personae and design cards may be used to help AT designers take into account specific needs of disability.

\section{Related work}

\subsection{Designing accessible interactive maps and tangible interactions}

Visual impairment has numerous consequences on cognitive development (Maurer et al. 2005), and especially on spatial cognition. Hence, there have been numerous research projects devoted to the design of assistive technologies that may improve spatial knowledge of visually impaired users (see Zeng and Weber 2011 and Brock et al. 2013 for reviews).

Tangible interaction relies on physical objects to interact with digital information. It allows simultaneous use of multiple modalities, and has been adopted in many prototypes for sighted users (Ullmer and Ishii 2000). A few research projects have aimed at designing accessible tangible devices for nonvisual exploration of maps. For instance, Pielot et al. (2007) designed interactive objects in order to explore maps with audio output.

\subsection{Understanding Use(r)s of Assistive Technologies}

Several authors investigating Assistive Technologies (ATs) acceptance rate have underlined the importance of the stigmatization associated to such devices (Polgar 2010). Some environmental features are quite obvious (access to the care system, lack of accessibility of public places, etc.), but others are less easy to identify and may be addressed with specific methods. 
The current study seeks to provide researchers with tools allowing for a better and wider description of users (including context and subjectivity) and their needs. For instance, Connors and Stalker (2006) identified that children experience disability as "impairment, difference, other people's reactions, and material barriers". When designing ATs, researchers should keep in mind that they are interfaces between: (1) the person living with impairment, including her subjective perception of herself and the world (Druin 2002); and (2) her social context. In addition, those interfaces should empower users (Hurst and Tobias 2011).

\subsection{Design Methods to Represent Users}

Visual impairment corresponds to a wide range of abilities, largely influenced by educational and social contexts. There are many variables to consider when describing visually impaired users. Although it would be a valuable solution to directly involve many children with diverse impairments in the design process (Druin 2002, Bailey et al. 2014), it is difficult to achieve, because of various constraints (e.g. availability, parental agreement, transportation and communication issues.).

When co-design is difficult or not possible, a method frequently used consists in the identification of representative users described as Personae (Friess 2012). Personae were proposed by Cooper (1999) as a tool for the design of interactions. They are fictitious but they embody characteristics that have been observed (e.g. professional roles, type of personality, social origins, personal history, goals, tastes, etc.). Personae are often represented with cards, and facilitate storytelling during the design process. Personae have been criticized because they represent idealized, "artificial" or stereotypical people. However, Pruitt and Grudin (2003) have pointed out that well-crafted personae are very helpful because they raise designers' sensitivity and empathy, and are an efficient communication tool within small and large teams. They may be part of a larger card deck (also including situations for example) and used in a variety of design activities, to serve as a communication tool between users and researchers (Wölfel and Merritt 2013).

\section{Motivation and Objectives}

A previous project on a similar topic had involved specialized teachers and visually impaired people in the design process, but not children (Brock et al. 2015). The results show that the device improved usability and satisfaction. But the designed prototype had not been implemented in the field. Furthermore, the HCI researchers involved in the project reported various design issues during work meetings. First, they lacked imagination, having difficulties coming up with new concepts of interaction techniques. Second, they were concerned by long term adoption of ATs. Many examples in the literature show that devices that have been successfully evaluated in the lab were not adopted in the field. Third, they were, in many brainstorming and evaluation sessions, working with a restricted number of users. They were afraid that this restricted population would not represent the whole targeted population. Finally, they reported that they did not manage to efficiently share notes and observations gathered in the field. 
Our current research project is based on co-design. It is conducted in a research laboratory including the HCI department of a computer science research centre, and an institute for visually impaired people. It also involves a designer, a specialist in psycho-ergonomics, a start-up developing open source software, and various stakeholders of the institute who volunteered to participate (orientation and mobility instructors, specialized teachers, transcribers, and visually impaired people).

In order to understand how the existing interactive map prototype may be adapted and adopted in the classrooms, but also to provide design guidelines for the new prototypes, we decided to conduct a longitudinal field-study and to develop new design processes. Following the field-study, we proposed a two day workshop with the HCI researchers for: (1) sharing the results and recommendations provided by the field study; (2) transmitting ideation methods coming from design research; and (3) developing usage scenarios of accessible interactive prototypes. A transversal goal was to encourage HCI researchers to take into account the physical, temporal and cultural context of the users in the design process, stimulate their empathy for users, and develop an understanding of their assumptions.

\section{Preliminary Field Study}

Our field study aimed to better understand the caring ecosystem of the Institute, and how caretakers (teachers, instructors, transcribers, etc.) use assistive technologies. This Institute hosts and assists hundreds of children and teenagers (up to 18 years old) living with visual impairments. It also provides rehabilitation and professional training for visually impaired adults.

\subsection{Methods}

The field-study consisted in twenty-seven semi-directed interviews between fifteen minutes and one hour depending on availability. Children were asked about their own experience of disability, usages of technologies, and topics of interests. Caretakers were asked about their definition of visual impairment, their roles in children's education and care practices. We also conducted four weeks of observations over six months. The results of this field-study have been reported elsewhere (Brulé et al. 2015). According to the grounded theory methodology (Charmaz 2006), they were open coded to identify concepts, and assembled by themes. In this paper, we only summarize the results that have supported the design of the workshop.

\subsection{Results}

About Children's experience of disability: First, the children reported feeling impaired when they were not able to engage in a given activity, or when they feared to failing at a task. This was especially the case for children whose 
impairment was late-detected, which is more likely to happen if they come from a low-income family with reduced access to the healthcare system. Second, they expressed feeling different, either in a positive or negative way. For instance, being able to use a smartphone without looking at it was seen as positive. But they may also feel excluded from mainstream culture, such as cinema. Third, they expressed being concerned about other people's reactions, such as other children insulting them. Finally the children expressed a consciousness of material barriers and the differences between accessibility policies and their application in everyday life.

On Caretakers' practices: First, caretakers highlighted the impact of the educational context, and especially of inclusion in traditional schools on children's abilities. The same impairment may have very different consequences depending on social and cultural background, as well as the specific care that children received (for instance, education in mainstream or specialized schools). Second, they felt having material barriers in their practices, including a lack of time, finances and technical resources. Third, they reported having strong commitments in raising public or political awareness, but also in sharing skills with others. Fourth, most of them engage in continuous and reflective learning: they constantly analyse and question their methods to improve their own skills and knowledge. Fifth, they are eager to use Do-It-Yourself or digital techniques to design adapted tools for the children they care for. Finally, the caretakers mentioned constructive experiences with researchers or new technologies as ways to improve their practices. They would work overtime on the project.

In conclusion, it appears that children experience disability not only as activity limitations but by numerous parameters that should be considered when designing ATs. In the next section, we present the results of the ideation workshop, to see how these findings can be transmitted, understood and used.

\section{Ideation Workshop}

\subsection{Design Cards}

The design cards used in the workshop were developed by the designer, relying on the field-study results and the aims of the workshop. The set was made of personae, places and goals cards with a specific structure. The personae cards included name and surname, but also a nickname, so that participants may refer to personae informally, and not via impairment, age or gender. Furthermore, the fieldstudy showed that context and subjectivity were important to understand usages. The cards aimed to provide personae with a social and cultural background, including date and place of birth, a general description, a list of topics of interest, as well as a personal history. An additional insert a portrait to be drawn. Finally, a field was reserved for the role(s) that personae had to play with the prototype (e.g. teaching, learning, helping, designing, etc.).

The field-study also revealed the importance of educational context (e.g. insertion in mainstream classrooms). Each place card described a location with spatial configuration and qualitative description (e.g. modern or ancient building, school, or museum). 
The goal cards were initially left blank. Because each caretaker has their own objectives. It was interesting to let participants elicit caretaker practices and the associated needs. They could freely fill in the cards including needs, tasks, skills to acquire, etc. (e.g. "knowing my own size compared to the world.")

\subsection{Activities}

The workshop was conducted with six HCI researchers involved in the project (including one blind and one visually impaired). The workshop facilitator observed the participants, and gathered results and feedback. After each activity, the results were presented and followed by a general discussion. The organizer specifically asked participants to react to the method and the results. The workshop consisted of four activitics.

Filling up persona, place, and goal cards. This activity was based on blank cards of three different types: persona, place and goal cards (Fig.1). Participants had one hour and a half to fill them, according to people, places or goals that could fit in the project. They could rely on people they had met, their office and the tasks they have to do. They also described persons that might use the intended prototype. The goal was to force participants to elicit how they were conceptualizing or stereotyping users.

There were four additional types of cards: "aesthetic" (e.g. minimalist or modern), "spatiotemporal context" (e.g. Canada 2020, India 2060, Moon 20120), "ludic mechanisms" (i.e. everyone is on the same team or against each other), and "qualitative" (i.e. the overall feeling expressed in the scenario). Ten of those cards were previously completed by the designer based on existing games.

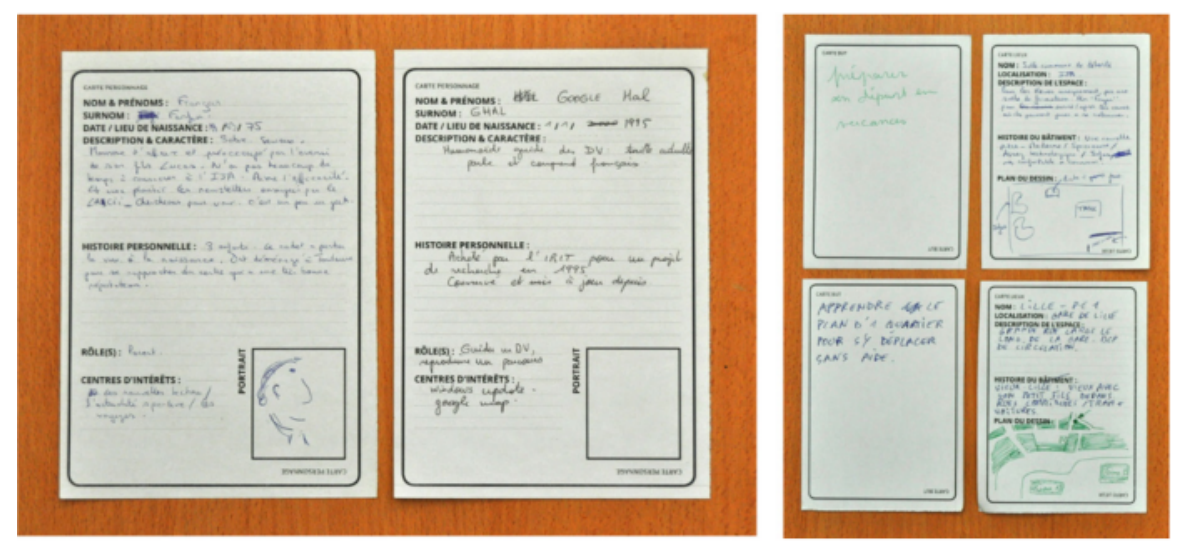

Fig. 1: From left to right: persona, goal and places cards, filled by workshop participants. We see that the personae were quite roughly described.

Imagining scenarios. Each group had to pick up three personae, one goal and one context, and imagine as many scenarios as possible with these cards. Participants 
had to write down as many scenarios as possible during two hours. Finally they were asked to perform some of these scenarios using everything they had at hand. The aim was for participants to better understand and describe users' subjective experiences.

Designing prototypes showing emotions. Participants were then asked to design prototypes displaying emotions. One participant selected an animal. The next participants successively picked up a temper (e.g. extrovert or nervous), and a feeling (e.g. surprised or hungry). Finally, the next participant had to describe an imaginary interactive table prototype that holds all these features (e.g. a table that looks and reacts like a surprised nervous kangaroo). Each group described two such prototypes with annotated sketches in twenty minutes. The goal was to mobilize cultural representations, i.e. a set of symbols used to communicate in a given culture.

Extended scenarios. The final activity focused on extending scenarios using the first card set (personae, places, and goals) completed with additional cards prepared by the facilitator (aesthetic, context, ludic mechanisms). The goal was to come up with completely new and speculative scenarios, as well as to extend the importance of cultural representations in scenarios.

\subsection{Results}

Filling up persona, place and goal cards. The participants filled 14 persona cards, 9 context cards and 12 goal cards. They wrote succinct descriptions of personae who were mainly defined by their "professional" role. The visually impaired personae were mostly described by impairment, which was not linked to a personal history. They did not contain any physical description, social background, etc. The context cards illustrated the institute classroom, various iconic buildings or speculative ones. The goal cards were mostly about acquiring new skills in geography or locomotion. There were no cards mentioning subjective, reflective or autotelic goals. The goals were highly pragmatic, thus minimizing the users' personal motivations.

Imagining scenarios. Each group came up with at least 10 to 15 scenarios. Some were pragmatic and could be immediately prototyped, such as $3 \mathrm{D}$ printing children figurines so that they could project themselves into a 3D model of a neighbourhood. Others were completely speculative, such as playing a game with a robotic dragon within a lunar station. They also proposed artistic settings, games or pedagogical activities. One group used many personae in scenarios, while the other group focused on goal and context cards, designing for one persona only. The participants willingly used objects found in the room (sugars, pencils, etc.) to illustrate ideas (Figure 2) but did not physically perform or play the scenarios.

Designing devices displaying emotions. The participants completed the task in less time than allocated. They all came up with rich, and annotated drawings of speculative devices. The blind participant provided verbal descriptions that were illustrated on a Dycem sheet by the facilitator. The prototypes included inventive techniques of interaction with various inputs and outputs (e.g. illumination, warming, shape changes, etc.) to express the emotional state of the device. 
Extended scenarios: The participants had difficulties in imagining scenarios making actual use of aesthetic or qualitative properties. The number of generated scenarios was still high, but they had to pick up new cards frequently to get inspiration. They thought that the number of parameters was too high, and sometimes too conflicted, in order to pull something interesting out. They nevertheless came up with highly creative scenarios (e.g. large scale interaction around the prototype) and described more enthusiastically their users (e.g. clothing or motivations), which illustrates a higher degree of empathy. They also described more precisely how users interact with the device (e.g. pitch of voice, object temperature, etc.)

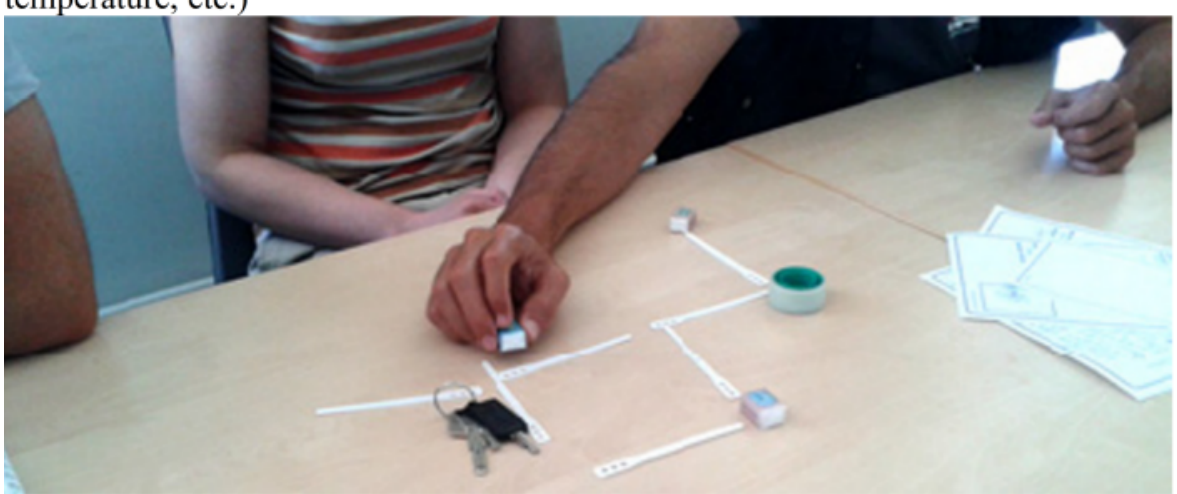

Fig. 2: Researchers prototyping scenarios with sugars, keys and other various objects

\subsection{Observations}

After each activity, the groups were asked to present outcomes to the others, and make comments on the activity and related aims. Although participants were used to working with scenarios, they reported having difficulties, especially in activities 3 and 4 ("Now I see that imagination is a muscle that should be flexed and trained much more"; "This is easy for you, but we are not used to it"). None of them had used similar methods before. When they were questioned about the activities and the relevance of the outcome on future research, they expressed uncertainty. They were unsure how to integrate these methods and results (e.g. the speculative scenarios) in their research activity. However, after discussion, several participants agreed that such a card set, describing potential users and goals, could be of use in the future. They emphasized that it helped them thinking outside of a task-oriented, pragmatic approach, which is often focused on impaired adults needs and experiences.

\section{Discussion}

The results of the field study (see Brulé et al. 2015 for extended results) were consistent with the literature on children's experience of disability. Disability encompasses many notions: feeling impaired, feeling different, a concern for 
others' reaction, or the existence of material barriers (Connors and Stalker 2006). The results also confirm the positive impact of inclusion (McGaha and Farra 2001, Holt et al. 2014) and the importance of rapid prototyping and new technologies (Hurst and Tobias 2011). In our case, it helped to structure the card set that was used in the workshop.

Concerning the workshop, it is interesting to note that the participants gradually proposed richer descriptions of users and interactions. Because none of them had experienced similar methods before, they were confused by the method, but also by the number of parameters. Nonetheless, it allowed them to avoid design fixations (Jansson and Smith 1991). Clearly, the workshop session led to propositions that would not have emerged from traditional brainstorming sessions. For instance, many scenarios involved interactions with rich input and output including haptics, gesture, light, temperature, etc. Some participants also described the pitch and the warmth of the prototype voice when interacting with children. On a short-term and pragmatic level, these quick ideation sessions confirmed the importance of tangible interactions, but also opened new perspectives to be prototyped and evaluated (e.g. the use of figurative objects).

However, the researchers expressed uncertainty about the "practical outcomes" of the workshop, and especially how speculative scenarios might help to design actual devices. During the discussion, the facilitator mentioned the risk of a design process mainly focused on functions and goals. They observed that it may lead to the exclusion of specific users or to failure to consider crucial aspects of interaction. They were reminded how models inherited from disability studies may help them develop other perspectives. In fact, the cards helped the researchers to think about their own practices (Schön 1983). By the end of the workshop, the participants were interested in using the design cards to better describe users, and to enable long term sharing of field observations and knowledge (the cards were preserved and may be reused). Furthermore, the card set can always be updated and may thus help framing future research projects. As co-design is not always possible, such cards may also be used by stakeholders to describe themselves and their goals.

\section{Conclusion}

The field-study helped us to better describe children living with visual impairment and how they interact with assistive technologies. It also showed how those interactions are shaped by a larger context (e.g. policy, culture, etc.) These observations guided the development of a set of design cards and workshop activities, which aim to improve the representation of users and increase empathy. In addition to the improvement of ideation within the team, the workshop also helped researchers to think about their knowledge of users, and highlighted how this knowledge may shape the design process. Future observations will estimate the impact it may have on the design practices within the team. 


\section{References}

Brock AM, Oriola B, Truillet P, Jouffrais C, Picard D (2013) Map design for visually impaired people: Past, present, and future research. Médiation et Information, Editions L'Harmattan, Paris, France, 36 : 117-129

Brock AM, Truillet P, Oriola B, Picard D, Jouffrais C (2015) Interactivity improves usability of geographic maps for visually impaired people. Human-Computer Interaction 30(2): 156-194

Brulé E, Bailly G, Gentes A (2015) Identifier les besoins des enfants en situation de déficience visuelle : état de l'art et étude de terrain. In: Proceedings of the IHM'15

Charmaz K (2006) Constructing grounded theory: A practical guide through qualitative analysis. Sage Publications

Connors C, Stalker K (2006) Children's experiences of disability - Pointers to a social model of childhood disability. Disability and Society 22(1)

Cooper A (1999) The inmates are running the asylum. Macmillan Publishing, Indianapolis, IN, USA

Druin A (2002) The role of children in the design of new technology. Behaviour and Information Technology 21(1): 1-25

Friess E (2012) Personas and decision making in the design process: An ethnographic case study. In: Proceedings of the CHI'12, Austin, TX, USA

Holt R, Moore AM, Beckett A (2014) Together through play: Facilitating meaningful play for disabled and non-disabled children through participatory design. In: Langdon PM,

Lazar J, Heylighen A, Dong H (Eds.) Inclusive designing: Joining usability, accessibility and inclusion. Springer

Hurst A, Tobias J (2011) Empowering individuals with do-it-yourself assistive technology. In: Proceedings of the 13 th International ACM SIGACCESS Conference on Computers and Accessibility, pp. 11-18, New York, NY, USA

Jansson DG, Smith SM (1991) Design fixation. Design Studies (12)1 Kinoe Y, Noguchi A (2014) Qualitative study for the design of assistive technologies for improving quality of life of visually impaired. In: Yamamoto S (Ed.) HIMI 2014, Part II, LNCS 8522

Maurer D, Lewis TL, Mondloch CJ (2005) Missing sights: Consequences for visual cognitive development. Trends in Cognitive Sciences 9(3): 144-151

McGaha CG, Farran DC (2001) Interactions in an inclusive classroom: The effects of visual status and setting. Journal of visual Impairment and Blindness 95(2): 80-94

Phillips B, Zhao H (1993) Predictors of assistive technology abandonment. Assistive Technology 5(1)

Pielot M, Henze N, Heuten W, Boll S (2007) Tangible user interface for the exploration of auditory city maps. In: Oakley I, Brewster S (Eds) HAID 2007, LNCS vol. 4813: 86-97, Springer Berlin Heidelberg, Germany

Polgar JM (2010) The myth of neutral technology. In: Oishi MMK, Mitchell IM, Van der Loos HFM (Eds.) Design and use of assistive technology, Springer, New York, NY, USA

Pruitt J, Grudin J (2003) Personae: Practice and theory. In: Proceedings of the 2003 Conference on Designing for User Experience, ACM Press, San Francisco, CA, USA

Schön DA (1983) The reflective practitioner: How professionals think in action. Basic, New York, NY, USA

Ullmer B, Ishii H (2000) Emerging frameworks for tangible user interfaces. IBM Syst. J.

Wright P, McCarthy J (2008) Empathy and experience in HCI. In: Proceedings of the SIGCHI Conference on Human Factors in Computing Systems, Florence, Italy

Wölfel C, Merritt T (2013) Method card design dimensions: A survey of card-based design tools. In: INTERACT 2013, vol. 8117: 479-846, Springer Berlin Heidelberg, Germany

Zeng L, Weber G (2011) Accessible maps for the visually impaired. In: Proceedings of IFIP INTERACT 2011 Workshop on ADDW, CEUR 